\title{
Variáveis que devem ser consideradas na avaliação da qualidade do relacionamento conjugal
}

\section{Variables that must be considered for the evaluation of marriage's quality}

\author{
Nicolau Kuckartz Pergher ${ }^{1}$
}

[1] Universidade Presbiteriana Mackenzie (MACK) e Núcleo Paradigma de Análise do Comportamento, Brasil | Título abreviado: Relacionamento conjugal | Endereço para correspondência: Rua Wanderley, 611. CEP: 05011-001. São Paulo, SP | E-mail: nicopergher@hotmail.com

Resumo: Clientes frequentemente procuram auxílio terapêutico com dúvidas, insatisfações e conflitos ligados a aspectos que envolvem relacionamentos afetivo-conjugais. No presente artigo, foram enumeradas variáveis que merecem serem investigadas na avaliação da qualidade de relacionamentos conjugais. As variáveis listadas e discutidas foram: (1) os motivos do início do relacionamento; (2) o histórico de relacionamentos de cada membro do casal; (3) a forma de divisão financeira; (4) as diferenças de idade entre os cônjuges e das culturas nas quais estiveram inseridos; (5) o grau de intimidade do casal; (6) as práticas sexuais; (7) os padrões de interação entre os cônjuges; (8) a existência de outras fontes de reforçamento fora do casamento; (9) o impacto das traições; (10) os efeitos da ocorrência de doenças em um dos cônjuges; (11) as decisões relacionadas aos filhos; (12) os planos de vida traçados pelo casal e (13) os aspectos relacionados à separação. As análises realizadas podem servir como material complementar para terapeutas que atendem clientes com queixas ligadas ao relacionamento conjugal, assim como podem funcionar como gerador de outras considerações teóricas e de pesquisas sobre o tema.

Palavras-chave: terapia, relacionamento conjugal, variáveis

\begin{abstract}
Clients often look for psychotherapy when they have doubts or conflicts concerning their marriage. In this paper, some variables for the evaluation of marriage's quality are listed. The variables considered were: (1) the reasons for the beginning of the relationship; (2) the history of relationships of each one involved; (3) the financial aspects; (4) the age and cultural differences; (5) the intimacy; (6) the sexual practices; (7) the interaction patterns between the couple; (8) the other reinforcements sources; (9) the betrayal impacts; (10) the diseases effects; (11) the decisions concerning kids; (12) the plans for life and (13) divorcing aspects. The analysis achieved can be used as a complementary material for therapists who deal with clients with relationships problems, as well as be useful for further theoretical considerations and researches about the subject.
\end{abstract}

Keywords: therapy, marriage, variables 
Clientes frequentemente procuram auxílio terapêutico com dúvidas, insatisfações e conflitos ligados a aspectos que envolvem relacionamentos afetivoconjugais (Otero \& Guerrelhas, 2003). Atualmente, casar jovem, virgem e permanecer casado pela vida inteira não é mais uma regra. Pelo contrário, existem diversos perfis de casais, cujos membros têm histórias de vida e práticas bastante idiossincráticas. Algumas das tendências mais recentes nos Estados Unidos são analisadas por Penn (2008). Dentre elas, o aumento no número de (a) mulheres solteiras, (b) casais formados entre colegas de trabalho, (c) casais que moram em cidades diferentes, $(\mathrm{d})$ casais que se conhecem pela internet, (e) uniões inter-raciais, (f) pessoas que passam a ter filhos em idades avançadas, (g) casais que preferem animais de estimação a filhos, (h) homens que assumem a orientação homossexual e (i) mulheres que têm relacionamentos com homens pelo menos dez anos mais novos. É plausível que existam tendências semelhantes no Brasil, além de outras que sejam típicas da nossa cultura nacional.

As propostas modernas de relacionamento conjugal apresentam certas resistências culturais quanto à sua aceitação plena e podem gerar sofrimento emocional nas pessoas que mantêm desejos e práticas passíveis de punição social, levando-as à terapia. Ainda que não haja grandes recriminações sociais em vigor, as pessoas muitas vezes sofrem por motivos ligados à relação conjugal, tornando esta o principal assunto de um processo terapêutico.

Considerando que um cliente fala eminentemente sobre dificuldades no relacionamento conjugal ao longo das sessões de terapia, é provável que exista insatisfação acerca da qualidade da relação. Entretanto, lamentar-se a respeito do relacionamento pode ser um comportamento clinicamente relevante (Kohlenberg \& Tsai, 1991/2001). O conteúdo das queixas pode ser coerente com um relacionamento que está ruim de fato, mas também se deve considerar que o comportamento de queixar-se esteja sendo mantido por atenção social, independentemente de haver problemas na relação conjugal.

Obviamente, um cliente que não fala sobre como está seu relacionamento não é sinônimo de que esteja tudo bem entre o casal. Evitar o assunto pode indicar esquiva. Além disso, o cliente pode não discriminar que ele próprio ou seu cônjuge esteja insatisfeito no relacionamento.

Por que o relacionamento não está bem? A pessoa está acomodada? Não propõe atividades conjuntas e não se esforça pelo bem-estar do casal? Não ama mais? O presente artigo pretende enumerar variáveis que merecem ser investigadas ao longo de uma terapia realizada individualmente, as quais servem para avaliar a qualidade de relacionamentos conjugais. Esse trabalho não pretende discutir estratégias terapêuticas gerais ou específicas para cada item identificado a seguir, mas pretende produzir estímulos discriminativos adicionais que possam auxiliar nas análises dos comportamentos dos clientes. Cabe ressaltar que o "diagnóstico" numa terapia analítico-comportamental é contínuo (Follette, Naugle \& Linnerooth, 1999), de maneira que nenhuma das considerações a seguir é exaustiva ou permanente em nenhum dos casos clínicos em andamento.

Cabe ressaltar, também, que cada assunto elencado a seguir mereceria uma revisão de literatura apropriada, muito mais extensa do que a realizada aqui. Entretanto, não é o objetivo deste artigo discutir pormenores de cada um dos assuntos, mas apenas citá-los com breves considerações. Nesse sentido, algumas análises aqui apresentadas envolvem generalizações amplas demais, as quais não contemplarão todos os indivíduos em atendimento terapêutico. Quanto à linguagem adotada, tipicamente serão utilizadas palavras como cônjuge ou casais. Contudo, as discussões realizadas a seguir não se aplicam unicamente a casais formal e legalmente unidos, mas também a quaisquer relacionamentos afetivo-conjugais estáveis e minimamente duradouros. O termo cliente está sendo utilizado geralmente no gênero masculino simplesmente para facilitar a coerência do texto, mas muitas análises valem indiscriminadamente para homens ou mulheres. Quando existir alguma consideração de gênero específica, ela estará devidamente apresentada. Embora o texto verse sobre relacionamentos heterossexuais, grande parte das considerações também pode ser aplicada a relacionamentos homossexuais. 


\section{Motivos do início do relacionamento}

O que atrai uma pessoa à outra? Uma investigação acerca das variáveis que controlaram o início do relacionamento é importante para identificar reforçadores para os clientes. Beleza física, status, fama, charme, simpatia, seriedade, ambição, possibilidade de controlar ou ser controlado, etc. Por que, dentre as inúmeras possibilidades existentes, foi com aquela pessoa específica que o cliente estabeleceu um relacionamento? Geralmente a resposta desse tipo de questão é complexa, e dificilmente os clientes têm uma descrição completa das variáveis relevantes, ao menos no início da terapia. Por outro lado, as respostas obtidas fornecem fortes evidências do que é considerado reforçador para o cliente.

Onde se conheceram? Em que circunstâncias? Já mantinha algum tipo de relação com a pessoa (colega de trabalho, amigo)? Como ambos os cônjuges conduziram o início do relacionamento? Como foi feita a definição quanto a estarem namorando ou não? Qual foi o intervalo de tempo entre a paquera e o primeiro beijo? Entre "ficar" e namorar? Entre namorar e morar junto ou casar? A lacuna temporal entre as diferentes fases do relacionamento pode indicar atitudes impulsivas, esquivas de compromissos, ou a existência de pressões sociais que apressem ou impeçam a união.

\section{Casar grávida}

Segundo Sidman (2003), engravidar precocemente pode ser uma forma de fugir da coerção exercida pela família nuclear, especialmente da mulher. Em outros casos, consciente ou inconscientemente, engravidar pode ser uma maneira de fazer com que o parceiro permaneça vinculado a si, particularmente quando ele está dando sinais de desistência do relacionamento.

\section{Uniões arranjadas}

Ainda existem casamentos arranjados, talvez mais nitidamente em casais praticantes de determinadas religiões. Nesses casos, o casal pode permanecer feliz e satisfeito, ou seus membros podem ressentir-se das pressões familiares para o casamento e terem, eles próprios, dúvidas quanto à possibilidade de manutenção da união.

\section{Histórico de relacionamentos}

\section{Histórico de rejeição}

O que faz alguém confiar em alguém? Possivelmente, confia-se mais naqueles que apresentam provas inequívocas de fidelidade e lealdade e/ou não se conhecem eventos que indiquem traições. A desconfiança, em contrapartida, sugere que haja atitudes dúbias ou desinformações por parte do parceiro e/ou que os comportamentos do cliente estão sob controle de relacionamentos anteriores, pautados por algum tipo de traição ou rejeição. É bastante comum a formulação de autorregras a partir de experiências com relacionamentos mal-sucedidos (conforme sugeriram Banaco, 2001; Colombini \& Pergher, 2009; Delitti, 2001; Guilhardi \& Oliveira, 2001), as quais podem tornar a pessoa insensível a oportunidades de reforçamento nos relacionamentos atuais.

Para clientes que foram, de alguma forma, rejeitados por seus parceiros, o fato de estarem sendo valorizados num relacionamento atual é especialmente importante. Entretanto, pequenos sinais de preterimento podem gerar comportamentos agressivos ou de desistência. Em indivíduos que tiveram algum histórico de abandono por seus cuidadores, sinais de rejeição podem ser especialmente relevantes (Reichenheim, Hasselmann \& Moraes, 1999; Williams, 2006). Também é importante investigar histórico de bullying: pessoas vítimas de violência física ou psicológica executadas por seus pares tendem a sentir-se menos passíveis de serem queridas por seus cônjuges (Palácios \& Rego, 2006).

\section{Relacionamentos tardios}

É esperado que as pessoas iniciem suas experiências de relacionamento na adolescência (Borges \& Schor, 2005): a primeira paixão, a primeira relação sexual, a conquista, o desapontamento, a constituição de um namoro, a intimidade compartilhada, etc. Alguns clientes revelam terem tido vivências escassas de relacionamentos durante a adolescência e início da vida adulta. Nesses casos, ao iniciar uma relação na vida adulta, é comum passarem pelo processo de auto-observação e descoberta pelo qual não passaram na adolescência. Nesse sentido, o terapeuta acaba tendo o papel de gerar consciência: auxiliar o cliente a discriminar dicas fornecidas 
pelo cônjuge, avaliar efeitos das decisões tomadas pelo cliente no relacionamento e investigar sentimentos gerados por eventos ocorridos no casal.

Além disso, é importante avaliar a que tipo de contingências o cliente está sujeito, já que a privação afetiva aumenta o valor reforçador do carinho, muitas vezes levando o cliente a subjugar-se ao cônjuge, tolerando imposições deste.

\section{Violência sexual}

Frequentemente, chegam às clínicas de psicologia mulheres (mais do que homens) que relatam, ao longo do processo terapêutico, terem sido vítimas de algum tipo de violência sexual durante a infância ou adolescência. Os efeitos de longo prazo da violência sexual variam entre os indivíduos. Alguns efeitos comuns são a dificuldade em colocar limites nas relações afetivas que estabelecem, tendência à revitimização, tendência à esquiva de relações com pessoas do sexo do agressor, reprodução da violência e promiscuidade (Amazarray \& Koller, 1998; Brino \& Williams, 2003; Ferrari, 2002). Naturalmente, quaisquer dificuldades nos relacionamentos atuais não podem ser atribuídas unicamente à violência sofrida, mas certamente eventos dessa ordem têm papel relevante e devem ser considerados na análise dos comportamentos dos clientes.

\section{Profissionais do sexo}

Algumas mulheres que já trabalharam como garotas de programa procuram terapia, muitas vezes com queixas ligadas a relacionamentos. Sentem culpa e vergonha por terem trabalhado como garotas de programa ou, pelo menos, receiam que seu passado seja revelado no relacionamento atual (Fonai \& Delitti, 2007). Além disso, no caso dos homens, é interessante investigar por que um determinado homem atrai-se por uma garota que é ou foi sabidamente uma garota de programa. Apesar das experiências sexuais com vários homens, é com ele que ela decide ficar? Ele gosta de ser o "herói" que vai destituí-la da vida promíscua? Ele sente algum tipo de prazer sexual com o fato de ela ter contato com outros homens?

\section{Excesso de exigência}

Alguns clientes decepcionam-se facilmente nos relacionamentos. Por vezes, há motivos factíveis para tais decepções. Em certos relacionamentos, entretanto, observa-se excesso de exigência em relação aos comportamentos que são pré-requisitos a um pretendente. Nesses casos, é preciso investigar padrões comportamentais de inflexibilidade, senso de justiça aguçado e baixa tolerância à frustração. Como agravante, com o tempo e um histórico de relacionamentos cada vez maior, as pessoas tendem a tornarem-se mais exigentes, diminuindo a probabilidade de comportamentos tolerantes e a possibilidade de relacionamentos amenos e agradáveis.

\section{Divisão financeira}

\section{O marido como provedor}

Embora as mulheres venham ganhando cada vez mais espaço no mercado de trabalho e obtendo suas próprias fontes de remuneração, ainda é bastante comum o formato de casamento no qual o marido é o provedor financeiro da casa. Mais do que isso, muito homens sentem-se na obrigação de produzir recursos financeiros para sustentar a casa e sofrem quando não conseguem fazê-lo por algum motivo qualquer. Segundo Skinner (1953/2000) e Baum (1999), aquele que detém o dinheiro, detém controle sobre o comportamento do outro. Na prática, a mulher pode sentir-se explorada e subjugada, enquanto o marido pode passar a cobrar determinadas posturas da mulher, "já que é ele quem está pagando”. Essa análise também vale para o cenário inverso no qual a mulher é provedora, e o marido, sustentado por ela.

Outro ponto potencialmente conflituoso é composto pelas situações em que o marido tem recursos financeiros consistentes, mas não provê para a mulher condições apropriadas e compatíveis com a renda. Nesse caso, a mulher sente-se desvalorizada e pode vir a questionar o quanto o marido deseja investir na relação conjugal.

\section{A mulher como provedora}

Ultimamente, as mulheres têm ampliado suas posições profissionais e seu salário, tendo, potencialmente, condições de lucrar tanto quanto homens. Essa nova condição parece introduzir variáveis culturais significativas aos relacionamentos conjugais 
modernos (Araújo, 2002; Fleck \& Wagner, 2003; Wagner, Predebon, Mosmann \& Verza, 2005). Algumas mulheres gostam do papel de provedora e podem encontrar homens que almejem serem sustentados por alguém, de maneira que nenhum dos membros do casal acaba sofrendo nessas condições. Ainda assim, a mulher pode vir a questionar-se sobre a adequação de seu papel no relacionamento e se ressabiar com eventuais interesses escusos do marido. Da parte do homem, também pode haver críticas sociais ao fato de estar sendo sustentado por uma mulher. Cabe destacar, também, que mulheres bem-sucedidas financeira e profissionalmente podem funcionar como estímulos aversivos para alguns homens, afastando-os.

\section{Conta conjunta}

Alguns casais possuem contas conjuntas, nas quais ambos fazem aportes e ambos têm liberdade para gastar como queiram. Dessa forma, enquanto houver recursos financeiros fartos, é possível que não haja conflitos, talvez "apenas" alguma desconfiança ou discordância de alguma das partes. Quando o casal estiver passando por dificuldades financeiras, é comum haver divergências quanto ao uso do dinheiro, o que pode gerar uma série de brigas, deflagrando outros desentendimentos, inclusive sobre outros temas.

É raro um casal que conversa, desde o início do relacionamento, sobre o que seria uma divisão financeira adequada e sobre o papel de cada um dos membros do casal na obtenção e divisão dos recursos (Teykal \& Rocha-Coutinho, 2007). Nessa direção, o terapeuta pode dar orientações em caráter preventivo e ficar atento a sinais de que a divisão financeira estabelecida esteja gerando insatisfações no cliente ou em seu cônjuge.

Alguns outros questionamentos são comuns e merecem que o terapeuta pondere juntamente com o cliente as consequências reforçadoras e aversivas de curto, médio e longo prazo, tais como: quem ficará responsável pela administração financeira da casa? Quem será encarregado de acumular recursos? É preciso ou desejável revelar o quanto cada um ganha? Cada um deve manter contas e economias individuais?

\section{Diferenças de idade e culturais}

\section{Diferenças de idade}

O mais comum, e talvez o mais aceito socialmente, é que os membros de um casal tenham idades próximas. Diferenças de idade sugerem geralmente a existência de momentos de vida diferentes entre os membros do casal. Portanto, é provável a existência de grupos sociais diferentes, com práticas e assuntos típicos distintos, o que pode ocasionar conflitos e dificuldade de convivência. Essas diferenças aparecem desde a época em que um está na escola, outro na faculdade; quando um está na faculdade e o outro está esforçando-se em início de carreira; quando um está em início de carreira e o outro já é um profissional experiente e bem-sucedido, etc. Nesses casos, é preciso avaliar eventuais críticas sociais acerca da diferença de idade. Um casal constituído por uma mulher de 40 ou 50 anos e um rapaz de 20 ou 30 pode ser vítima de recriminações sociais. Essas críticas são ainda mais severas em casos de relacionamentos com crianças ou adolescentes e em casos de gerontofilia, o que gera sentimentos de culpa e indignidade muito exacerbados em clientes que se sentem atraídos por indivíduos muito novos ou muito mais velhos. É importante verificar por que os clientes sentem-se atraídos por pessoas que têm idades distantes da sua. Houve alguma história de punição para relacionamentos afetivos tradicionais? A pessoa perdeu sua mãe ou pai e encontra no cônjuge mais velho uma relação semelhante à que teria com seus progenitores? Existe interesse econômico? Busca proteção?

\section{Diferenças culturais}

Considerando as colocações de Baum (1999), a cultura pode ser definida como sendo constituída pelas práticas verbais e não verbais que determinado grupo compartilha. Num casal, cada indivíduo esteve inserido em uma família, cujas práticas foram possivelmente diferentes daquelas da família alheia. Algumas discrepâncias culturais tornam-se evidenciadas quando existem diferenças étnicas entre os membros do casal (e.g., negros e brancos, orientais e ocidentais, etc.). Outras diferenças culturais são deflagradas em casais compostos por pessoas de nível sócio-econômico diferente e que, portanto, tendem a ter seus comportamentos reforçados por 
estímulos que não necessariamente são reforçadores para o cônjuge (e.g., um churrasco de lingüiça versus o restaurante mais fino da cidade). Nesses casos, além de eventuais pressões exercidas contra a união do casal, ambos os cônjuges passam a ter de desenvolver repertórios comportamentais novos, $\mathrm{o}$ que pode ser bastante oneroso, levando à desistência do relacionamento.

Para ilustrar a manifestação do choque cultural entre famílias, pode-se considerar o exemplo de uma família que tem por hábito encontrar-se todos os finais de semana e compartilhar amplamente os acontecimentos recentes. Nesse caso, costuma ser descrita como uma família "unida", porém seus membros podem sentir-se expostos e vulneráveis aos comentários dos familiares. Em contraposição, algumas famílias não têm o hábito de manter contato frequente e são descritas como famílias distantes ou frias. Cabe ressaltar que cada um desses perfis familiares pode ser agradável ou desagradável para diferentes pessoas, o que deve ser avaliado: o cliente esforça-se para estar com sua família ou com a família do cônjuge? O cliente evita estar em família? Quais são os reforçadores concorrentes a estar com determinada família?

Os seres humanos com frequência imitam uns aos outros. Particularmente, as pessoas tendem a imitar seus pais em diversos aspectos. No que concerne a relacionamentos, que tipo de modelos o cliente e seu cônjuge tiveram? Eles são coerentes e compatíveis entre si? São modelos que o cliente gostaria de alcançar e não consegue? São antimodelos: o que controla o comportamento do cliente é fazer exatamente o oposto do que os pais fizeram?

\section{Graus de intimidade}

Intimidade refere-se à emissão de comportamentos passíveis de punição em outras relações sociais (Cordova \& Scott, 2001). Considera-se que os cônjuges são íntimos quanto mais compartilharem suas vivências do dia-a-dia, inclusive de conteúdos passíveis de recriminação social. Alguns conteúdos compartilhados que sugerem intimidade são relatos sobre dificuldades no trabalho (seja de relacionamento no trabalho, seja de questionamentos quanto à competência para a realização de determinadas tarefas), opiniões sobre comportamentos de pessoas com quem os membros do casal convivem, expressão de vontades ligadas às relações sexuais. Relacionamentos íntimos e pautados por cumplicidade tendem a ser mais dificilmente esquecidos e são constantemente rememorados, possivelmente devido ao reforçamento maciço que esteve em vigor.

Clientes que mantêm relacionamentos superficiais, perenes e instáveis podem ter dificuldade de tornarem-se íntimos de outras pessoas, isto é, de tornarem-se vulneráveis à punição por parte do cônjuge. Possivelmente, nesses casos, exista alguma história de rejeição ou de relacionamentos nos quais o outro "aproveitou-se" do cliente, gerando sofrimento. Frequentemente, relacionamentos superficiais acabam inclusive afastando o pretendente, que não se sente incluído e devidamente valorizado pelo cliente.

Ainda, pode haver clientes que tendem a tornar demasiadamente íntimas relações que se encontram num estágio muito inicial, propondo encontros excessivos e planos ambiciosos para o futuro do casal, o que pode afugentar o cônjuge. É comum, também, encontrar indivíduos que adotam postura sedutora nas diferentes relações que estabelece, descrevendo dificuldades de levar a cabo relacionamentos monogâmicos duradouros.

\section{Práticas sexuais}

Os transtornos sexuais são cada vez mais frequentes (Rodrigues, 2000, 2001; Rosseto, Rodrigues, Zeglio \& Catão 2006). Vaginismo, ejaculação precoce e dificuldade de ereção estão entre algumas das queixas mais comuns. Excluindo as causas orgânicas, as falhas na resposta sexual sugerem ou produzem dificuldades no casal. É importante uma investigação acerca da frequência e da qualidade das relações sexuais para ambos os membros do casal. Entretanto, esse é um assunto delicado, que merece a utilização de audiência não-punitiva, além de uma relação terapêutica bem-estabelecida. A resposta sexual costuma refletir a qualidade da relação e/ou da qualidade de vida de cada membro do casal (Rodrigues, 2000, 2001). Independentemente de haver algum transtorno sexual (do ponto de vista psiquiátrico), é comum algum dos membros do casal estar insatisfeito com a frequência e/ou com a qualidade das relações sexuais. Nesse sentido: algum dos membros do casal está sendo muito exigente? Alguém tem uma história de punição e de restrições severas 
relacionadas à prática sexual? Existe perda do valor reforçador do sexo? Os indivíduos sabem e conseguem expressar suas percepções e desejos quanto às relações sexuais? Como o outro recebe essas manifestações?

Afora as práticas sexuais mais convencionais, alguns casais aderem a trocas de casais, convidam outras pessoas para participar da relação sexual, utilizamse de recursos de fantasia e objetos para incrementar o sexo e assistem a filmes eróticos conjuntamente, para citar algumas das práticas adotadas. Nesses casos, é importante avaliar se a atividade sexual está sendo igualmente reforçadora para ambos, ou se existe algum grau de sofrimento emocional na utilização desses recursos adicionais.

\section{Padrões de interação \\ Vigilância}

Alguns clientes exercem e/ou são vítimas de vigilância exacerbada (inspecionar extratos de bancos, ligações e mensagens de celular, e-mails, acompanhar a comunicação do cônjuge em sites de relacionamentos, monitorar horários, seguir o cônjuge, contratar detetives particulares) (Buss, 2000; Costa, 2005). Nesses casos, é necessário avaliar se existem evidências que justifiquem tais checagens ou mesmo se o cônjuge está buscando justificativas para embasar o término do relacionamento. Cabe destacar que, se os comportamentos investigatórios e inquisitórios se mantêm, deve-se avaliar de que forma o cônjuge-vítima acaba alimentando esse tipo de comportamento.

\section{Comunicação indireta}

É possível que uma determinada pessoa não fale diretamente o que pensa ou deseja para outra (Elias \& Britto, 2007; Fowers, 2001; Silva \& Vandenberghe, 2009). Para tal, acaba utilizando-se do recurso de contar para terceiros, com a finalidade de que a informação chegue ao cônjuge. Muitas vezes, membros da família acabam exercendo esse papel de "pombo-correio".

\section{Competição}

Os membros de um casal frequentemente podem competir entre si, seja por reconhecimento social, seja disputando quem recebe mais dinheiro, seja quanto à direção correta de conduzir a educação dos filhos. Muitas vezes, acabam inclusive denegrindo e subjugando publicamente o cônjuge. Como qualquer alternativa de comportamento fundamentada em controle aversivo, esse padrão de interação está fadado a gerar contracontrole e sentimentos ruins (Sidman, 2003), geralmente tornando o relacionamento inviável nesses moldes.

\section{Quem toma as decisões}

Alguns casais são compostos por uma pessoa que decide as atividades e planos do casal e outra que acata as decisões. A pessoa que segue as determinações de outrem pode sentir-se insegura e pode ter um padrão de comportamento dependente, talvez nem vindo a sofrer com o fato de acatar as deliberações do cônjuge. Contudo, pode sentir que não tem autonomia e pode sentir-se desconsiderada nas decisões. No limite, pode haver descrições do tipo "Deixei minha vida para viver a vida do outro". Por outro lado, a pessoa que toma as decisões (embora possa gostar desse papel e até evitar que seja destituído dessa tarefa) às vezes passa a cobrar maior participação do cônjuge.

\section{Gabar-se}

Algumas pessoas podem sentir-se atraídas por aqueles que enaltecem suas façanhas, qualidades e conquistas. Entretanto, o convívio com alguém que se gaba torna-se frágil caso não seja correlacionado com atitudes de consideração pelo outro. As pessoas que destacam seus feitos geram admiração no curto prazo, mas podem tornar-se insensíveis e desagradáveis no médio prazo, gerando descontentamento acerca do relacionamento conjugal. Cabe lembrar que Skinner (1953/2000) já analisava que o indivíduo que se vangloria de seus feitos pode estar esquivando-se de entrar em contato com seus próprios defeitos, não os assumindo.

\section{Agressividade}

Diversos comportamentos podem ser incluídos em uma classe de respostas genericamente denominada de agressividade. Aliás, existem variações na própria definição de agressividade (cf. Regra, 2000). Por outro lado, a agressividade é possível de ser avaliada observando-se se existem efeitos típicos do controle aversivo na pessoa (supostamente) agredida (Cherek \& Dougherty, 1997; 
Sidman, 2003). Geralmente, o agressor possui um repertório comportamental reduzido para manter relacionamentos, restrito à imposição de atitudes agressivas (Pinheiro, Haase, Del Prette, Amarante \& Del Prette, 2006). A pessoa agredida sente emoções ruins e muitas vezes receia inclusive as punições provenientes do cônjuge em uma eventual separação. Salvo algumas histórias particulares em que um padrão masoquista foi gerado por meio do pareamento sofrimento-afeto (fazendo com que a pessoa "goste" de sofrer), a agressão tende a gerar contracontrole e fuga por parte do cônjuge.

\section{Fontes de reforçamento extracônjuge}

Os membros do casal mantêm momentos de independência (e.g., sair com amigos, fazer cursos, esportes)? Existe equilíbrio entre momentos individuais e atividades conjuntas do casal? Algum dos membros do casal está insatisfeito quanto à sua independência ou quanto à individualidade exacerbada do cônjuge? Como o cliente sente-se na ausência do cônjuge: sente saudades? Ciúmes? Alívio? Orgulho? Nesse ínterim, os sentimentos podem ser pistas para as contingências em vigor, conforme sugeriram Skinner (1989/1995) e Banaco (1999). A depender do sentimento descrito, pode-se verificar se o cônjuge está funcionando como estímulo reforçador positivo ou negativo.

Costuma ser um grande desafio conseguir manter uma vida independente concomitante à satisfação no relacionamento conjugal. Esse desafio torna-se especialmente difícil quando o relacionamento passa por períodos difíceis e os membros do casal passam a conviver com grupos sociais onde existam outras pessoas que funcionam como fontes de reforçamento, levando os membros do casal a se encantarem por essas pessoas, em detrimento da valorização do casamento.

Muitas vezes, também se observa que o cliente atribui ao cônjuge a responsabilidade pela oferta de reforços. Manter uma pessoa como a única ou prioritária fonte de reforços pode ser bastante arriscado: caso o relacionamento se encerre, o cliente perderá enorme magnitude de reforços positivos, ao menos no curto prazo.

\section{Traições}

Primeiramente, é importante caracterizar o que seria uma traição - e aí se tem definições bastante variadas para cada cliente: olhar para outras pessoas, manter contato com pessoas do sexo oposto em sites de comunicação, acessar pornografia na internet, sair para jantar com um(a) colega de trabalho, ter conjunção carnal de qualquer ordem, etc (Costa, 2005; Leite, 2000). Ou seja, no que se refere a traições, aquilo que funciona como estímulo aversivo para alguém pode ser bastante particular e diferente do que o cônjuge considera traição. Nesse ínterim, já pode haver uma série de discussões entre os membros do casal. De qualquer forma, a pessoa traída vê-se obrigada a tomar decisões: fingir que não sabe, perdoar, vingar-se na mesma "moeda", tentar entender os motivos da traição, separar-se, entre outros. Cada uma dessas alternativas gerará tanto consequências reforçadoras quanto outras consequências aversivas adicionais, fazendo com que a pessoa sinta-se confusa e em conflito por algum período de tempo. De qualquer forma, a pessoa traída costuma ter ressentimentos, que tendem a ser mais intensos quanto mais a pessoa tenha se esforçado e se comportado em prol do outro. Outro relato comum é de perda de confiança no parceiro, e geralmente essa confiança demora para ser reestabelecida.

É importante, também, entender as variáveis presentes e históricas que levam uma pessoa a trair ou se engajar em um relacionamento extraconjugal. A pessoa pode ter um histórico de ter sido traída, ela própria, ou pode ter conduzido diversas traições sem consequências aversivas que fizessem esse comportamento ser suprimido. Em adição, embora não seja uma regra amplamente válida, é bastante provável que haja algum grau de insatisfação quanto à vida conjugal atual.

\section{Doenças}

\section{Abuso de drogas}

Alguns clientes reclamam de que o cônjuge tem uma história de abuso de drogas. As drogas podem tornar-se fontes de reforçamento poderosas e podem passar a ser a única fonte de reforçamento para uma pessoa, que deixa de receber reforçamento social e reforçamento advindo da ocupação pro- 
fissional (Benvenuti, 2004, 2007). Nesses casos, o cliente tem receios quanto ao futuro do casal, pensa em separar-se, mas, por outro lado, pensa que deve ajudar o cônjuge e muitas vezes sente-se responsável pela drogadição. Se o cliente mantém o relacionamento a despeito do uso de drogas do cônjuge e de eventuais agressões que possam ocorrer, é preciso investigar possíveis reforçadores que o cônjuge ainda provê, sejam afetivos ou financeiros. Ainda, é preciso considerar eventuais ameaças sociais em caso de separação, de maneira que o cliente pode permanecer no relacionamento por esquiva de recriminação social.

\section{Depressão}

Cada vez mais comum na sociedade moderna, a depressão de um dos membros do casal introduz variáveis importantes no relacionamento (Mead, 2002; Schestatsky \& Fleck, 1999). O indivíduo em depressão perde seu poder como fonte de reforços para o outro. A pessoa que convive com o indivíduo em depressão sente-se impotente em conseguir ajudar. Muitas vezes, acaba tendo o ônus de sustentar financeiramente a casa, fazendo com que passe a exigir determinadas posturas da pessoa em depressão. Nesses casos, precisa-se pensar nas contingências responsáveis pela depressão, especialmente em histórias de incontrolabilidade ambiental e estresse crônico e moderado (cf. Hunziker, 1982, 1993; Thomaz, 2005, 2009). Quanto ao indivíduo que convive com o depressivo, é importante analisar se ele próprio não estaria gerando ou agravando o quadro clínico por meio de cobranças excessivas, ou reforçando positivamente com atenção social os comportamentos depressivos.

\section{Outras doenças psiquiátricas}

Muitos outros diagnósticos poderiam ser citados e analisados aqui, tais como Transtorno Afetivo Bipolar, Transtornos de Personalidade e Transtornos de Ansiedade. Epidemiologicamente, os diagnósticos psiquiátricos vêm tornando-se mais comuns e mais conhecidos. Em quaisquer casos, o terapeuta analítico-comportamental deveria considerar o quanto o cliente contribuiu para o surgimento da doença psiquiátrica do cônjuge ou de que forma ele foi exposto a contingências manejadas pelo cônjuge que funcionaram como "gatilho" para a doença.

\section{Doenças crônicas e terminais}

A convivência com uma doença crônica ou terminal não costuma ser fácil nem para o portador da doença, nem para seus familiares. Quando um dos membros do casal tem uma doença que traz algum grau de comprometimento das atividades de vida diária, é comum haver sofrimento emocional de ambas as partes. Embora possa ser prazeroso receber cuidados de outrem e eximir-se da realização de determinadas tarefas, a existência de um comprometimento da rotina e das possibilidades de obtenção de reforçadores pode ser bem dolorida. $\mathrm{O}$ cônjuge passa a ter de tomar providências em relação ao doente. Passa a ter conflitos entre cuidar do outro e investir em sua vida pessoal e entre memórias boas do passado e impossibilidades do presente. No limite, tem de aprender a considerar a perda da pessoa e a retomar a individualidade, sem a presença do outro (Brown, 1995).

\section{Filhos}

\section{Aborto}

Embora a prática do aborto seja legalizada em apenas alguns poucos casos, ela é bastante frequente. É improvável que alguém goste de abortar. O aborto induzido é criticado socialmente e, especialmente, por agências de controle ligadas à religião. A decisão por abortar costuma ser fruto de uma avaliação dramática que acaba por considerar que a vinda de um filho (naquele momento específico, pelo menos) atrapalharia a vida de uma ou ambas as pessoas do casal. A mulher que aborta (geralmente mais do que o homem) sofre de culpa e reflete se deveria ter feito aquilo e como teria sido sua vida com um filho (Costa, Hardy, Osis \& Faúndes, 1995; Osis, Hardy, Faúndes, Alves \& Balarezo, 1994). Se o casal permanece junto após o aborto, passa a existir um evento sobre o qual muitas vezes não se conversa, muito menos publicamente. Também é importante entender se a decisão pelo aborto foi conjunta, ou unilateral. Se só a mulher decidiu, é provável que o marido sinta-se traído ou desgostado. Se foi o marido quem decidiu, é possível que a mulher sinta-se pressionada e venha eventualmente a responsabilizar o marido por sua infelicidade. A decisão de ter um filho, a partir disso, pode ser envolta de culpa pelo ato cometido anteriormente, ou exaustivamente pensada para assegurar a maior garantia de rea- 
lização pessoal possível. Se o casal não permanece mais junto, especialmente para a mulher, a decisão de ter filhos no futuro costuma ser um tema delicado e repleto de inseguranças.

Abortos espontâneos, embora não tenham sido deliberados, podem ser vivenviados como incapacidade da mulher em ter filhos (Rodrigues \& Hoga, 2005). Quando a gravidez prossegue, o casal costuma ter receios quanto à sobrevivência do filho e, muitas vezes, vivencia sentimentos ambíguos: aquele filho é a vitória do casal e é o depositário de todas as expectativas dos pais, mas também há certa ambivalência acerca do quanto se pode envolver afetivamente com aquele filho (já que outras vezes envolveram-se, e o filho não "vingou").

\section{Decisão de ter filhos}

Existem cobranças sociais para que um casal em relação estável e já estabelecido profissionalmente tenha filhos - algumas vezes, existem cobranças até antes disso. Ainda assim, alguns casais, em comum acordo, decidem não ter filhos e desfrutar de outros reforçadores (tais como viagens constantes). Esses casais, chamados de "dinks" (double income no kids, ou seja, "dupla renda, sem crianças"), passam a ter de responder às perguntas feitas por seus pares e defender sua proposta (cf. Morgan, 1994). Entretanto, o mais comum é que um dos membros do casal queira ter filho e o outro não. Esse fato pode gerar sentimentos de decepção e desconfiança quanto ao futuro da relação. Dificilmente, a decisão de ter filhos é tomada sem algum nível de divergência quanto ao momento de tê-los, quanto aos critérios necessários para configurar o "momento certo" ou mesmo quanto à motivação para se ter filhos ou não (Rios \& Gomes, 2009).

Em outros casos, a decisão de ter filhos ocorre num contexto em que o casal não está bem, de forma que um filho traria novos reforçadores e faria com que o casal passasse a conviver bem. Essa "estratégia" pode dar certo, ou não.

\section{Tratamentos para engravidar}

Não basta decidir ter filhos; é preciso engravidar. E nem sempre esse processo é tão fácil. Alguns casais, após inúmeras tentativas fracassadas, acabam recorrendo a tratamentos para engravidar. Muitas vezes, esses tratamentos exigem certas discipli- nas do casal e suscitam uma série de sentimentos (cf. Costa, 1995). É possível que um dos membros seja culpabilizado pela infertilidade, que se criem expectativas demais em relação aos resultados do tratamento e que se questione até que ponto devese chegar para ter filhos. Nesse ínterim, também se discute a possibilidade de adoção e todos os prós e contras dessa outra decisão.

\section{Teste de DNA}

Hoje em dia, é possível certificar-se se alguém é pai ou não de um indivíduo. A exigência do teste de DNA indica desconfiança por parte do marido em relação à fidelidade da mulher ou simplesmente um padrão comportamental de insegurança (cf. Fonseca, 2005). A mulher que tem certeza da paternidade dos filhos sente-se ofendida e humilhada com esse tipo de exigência, diminuindo, nela própria, a motivação para continuar o relacionamento com aquela pessoa. A deflagração de que o filho não seria de quem se pensa que é gera uma série de conflitos no casal, além de potenciais recriminações sociais.

\section{Estilos parentais}

Para os casais que têm filhos, as decisões acerca da educação dos filhos podem gerar diversos conflitos passíveis de serem tópicos de terapia. Sabe-se que existem diversas maneiras de conduzir a educação algumas delas descritas sob o rótulo de "estilos parentais" (Gomide, 2003). Considerando os padrões diametralmente opostos - autoritário e permissivo (e suas nuances) -, é possível que um dos cônjuges adote uma dessas posturas, e outro defenda a postura oposta. Além de um provável efeito indesejável no próprio filho, pode haver grandes desavenças no casal sobre esse tema.

\section{Independência dos filhos - Síndrome do "ninho vazio"}

Em algumas obras sobre Psicologia do Desenvolvimento (p. ex. Bee, 1997), encontra-se descrito o fenômeno do "ninho vazio". Essa é uma metáfora utilizada para descrever a fase da vida (tipicamente a partir da adolescência) na qual os comportamentos dos filhos passam a serem eminentemente reforçados por estímulos alheios àqueles providos pelos pais. Na prática, é uma fase do 
desenvolvimento em que o casal encontra-se mais sozinho (na ausência dos filhos, que passam muito tempo fora de casa, inclusive indo morar sozinhos) e se vê obrigado a reavaliar o relacionamento conjugal, questionando se a convivência enquanto casal ainda é possível e como.

\section{Planos de vida}

O cliente ou seu cônjuge mantém planos para o futuro do casal: viagens, aquisição de bens, etc? Investe no relacionamento: convida para um programa a dois, inicia uma conversação, compartilha eventos do dia-a-dia? O cliente consegue imaginarse com aquela pessoa daqui a 10, 20 anos? Em que circunstâncias? Embora o futuro, em sua integridade, seja bastante difícil de prever com precisão, simular um momento abstrato no futuro serve para dar parâmetros da qualidade do relacionamento atual, do que precisaria ser modificado para que o casal permaneça unido e do quanto os planos de cada um incluem e valorizam o outro.

\section{Separação}

A decisão de separar-se não costuma ser tarefa fácil. Aliás, uma decisão de separação tomada facilmente indica que o relacionamento estava claramente aversivo, de forma que a separação gera sentimentos de alívio. Outra possibilidade é que a separação seja uma amostra de comportamento impulsivo de um dos cônjuges, o que também deve ser considerado.

Geralmente, entretanto, a separação efetiva decorre de um processo de reflexão no qual pesam sentimentos de frustração, de incapacidade na manutenção de um relacionamento e lembranças de bons momentos que o casal teve junto. É comum a identificação de sentimentos de indiferença em relação ao cônjuge e relatos de que "não ama mais" ou de que se tornaram apenas amigos; não mais marido e mulher (Feres-Carneiro, 1998).

Ao separar-se, é preciso identificar se o casal ainda mantém contato, com que frequência e que tipo de interação resta entre eles. Essa interação pode ser suficiente e reforçadora para ambos, mas também pode haver desgosto ou manutenção da esperança de reatar o relacionamento de alguma das partes.

Concluindo, o presente artigo teve como objetivo enumerar algumas variáveis que devem ser consideradas na avaliação da qualidade do relacionamento conjugal. Muito provavelmente, os tópicos abordados não abarcam todos os fatores relevantes num relacionamento de casal. Ainda assim, as variáveis e as hipóteses de análise funcional levantadas podem auxiliar os terapeutas a compreender fatores importantes e, espera-se, podem ser úteis na produção de material teórico e de pesquisas que corroborem, refutem ou complementem as discussões aqui realizadas.

\section{Referências}

Amazarray, M. R., \& Koller, S. H. (1998). Alguns aspectos observados no desenvolvimento de crianças vítimas de abuso sexual. Psicologia: Reflexão e Crítica, 11(3), 559-578.

Araujo, M. F. (2002). Amor, casamento e sexualidade: Velhas e novas configurações. Psicologia: Ciência e Profissão, 22(2), 70-77.

Banaco, R. A. (1999). O acesso a eventos encobertos na prática clínica: Um fim ou um meio? Revista Brasileira de Terapia Comportamental e Cognitiva, 1(2), 135-142.

Banaco, R. A. (2001). Auto-regras e patologia comportamental. Em D. R. Zamignani (Org.), Sobre comportamento e cognição: Vol. 3. A aplicação da análise do comportamento e da terapia cognitivo-comportamental no hospital geral e nos transtornos psiquiátricos (pp. 80-88). Santo André, SP: Esetec.

Baum, W. M. (1999). Compreender o behaviorismo: Ciência, comportamento e cultura. Porto Alegre, RS: Artes Médicas.

Bee, H. L. (1997). O ciclo vital. Porto Alegre, RS: Artes Médicas.

Benvenuti, M. F. (2004). Condicionamento respondente: Algumas implicações para o desenvolvimento de tolerância, síndrome de abstinência e overdose. Em C. N. Abreu \& H. J. Guilhardi (Orgs.), Terapia comportamental e cognitivocomportamental: Práticas clínicas. São Paulo, SP: Roca.

Benvenuti, M. F. (2007). Uso de drogas, recaída e o papel do condicionamento respondente: Possibilidades do trabalho do psicólogo em ambiente natural. Em D. R. Zamignani, R. Kovac, \& J. S. Vermes (Orgs.), A clínica de portas abertas: Experiências e fundamentação do acompa- 
nhamento terapêutico e da prática clínica em ambiente extraconsultório. Santo André, SP: Esetec.

Borges, A. L. V., \& Schor, N. (2005). Início da vida sexual na adolescência e relações de gênero: Um estudo transversal em São Paulo, Brasil, 2002. Cadernos de Saúde Publica, 21(2), 499-507.

Brino, R. F., \& Williams, L. C. A. (2003). Capacitação do educador acerca do abuso sexual infantil. Interação em Psicologia, 7(2), 1-10.

Brown, F. H. (1995). O impacto da morte e da doença grave sobre o ciclo de vida familiar. Em B. Carter \& M. McGoldrick (Orgs.), As mudanças no ciclo de vida familiar (pp. 393-412). Porto Alegre, RS: Artes Médicas.

Buss, M. D. (2000). A paixão perigosa. Rio de Janeiro, RJ: Objetiva.

Cherek, D. R., \& Dougherty, D. M. (1997). The relationship between provocation frequency and human aggressive responding. The Psychological Record, 47, 357-370.

Colombini, F. A., \& Pergher, N. K. (2009). Decisões clínicas na terapia analítico-comportamental. Acta Comportamentalia, 17(2), 235-253.

Cordova, J. V., \& Scott, R. L (2001). Intimacy: A behavioral interpretation. The Behavior Analyst, 24(1), 75-86.

Costa, N. (2005). Contribuições da psicologia evolutiva e da análise do comportamento acerca do ciúme. Revista Brasileira de Terapia Comportamental e Cognitiva, 7(1), 5-14.

Costa, R. G. (1995). Concepções sobre maternidade entre mulheres que buscam tratamento para esterilidade (Dissertação de Mestrado não-publicada). Universidade de Campinas, Campinas, SP.

Costa, R. G., Hardy, E., Osis, M. J .D., \& Faúndes, A. (1995). A decisão de abortar: Processo e sentimentos envolvidos. Caderno de Saúde Pública, 11(1), 97-105.

Delitti, M. (2001). Análise funcional: O comportamento do cliente como foco da análise funcional. Em M. Delitti (Org.), Sobre comportamento e cognição: Vol. 2. A prática da análise do comportamento e da terapia cognitivo-comportamental (pp. 37-44). Santo André, SP: Esetec.

Elias, P. V .O., \& Britto, I. A. G. S. (2007). A função da assertividade no relacionamento afetivo. Em R. R. Starling (Org.), Sobre comportamento e cognição: Vol. 19. Temas aplicados (pp. 23-36). Santo André, SP: Esetec.

Feres-Carneiro, T. (1998). Casamento contemporâneo: O difícil convívio da individualidade com a conjugalidade. Psicologia: Reflexão e Crítica, 11(2), 379-394.

Ferrari, D. C. A. (2002). Definição de abuso na infância e adolescência. Em D. C. A Ferrari \& T. C. Vecina (Orgs.), O fim do silêncio na violência familiar: Teoria e prática (pp. 81-94). São Paulo, SP: Ágora.

Fleck, A. C., \& Wagner, A. (2003). A mulher como a principal provedora do sustento econômico familiar. Psicologia em Estudo, 8(2), 31-38.

Follette, W. C., Naugle, A. E., \& Linnerooth, P. J. (1999). Functional alternatives to traditional assessment and diagnosis. Em M. J. Dougher (Org.), Clinical behavior analysis (pp. 99-125). Reno, NV: Context Press.

Fonai, A. C. V., \& Delitti, M. (2007). Algumas contingências mantenedoras do comportamento de prostituir-se. Revista Brasileira de Terapia Comportamental e Cognitiva, 9(1),103-113.

Fonseca, C. (2005). Paternidade brasileira na era do DNA: A certeza que pariu a dúvida. Cadernos de Antropología Social, 22, 27-51.

Fowers, B. J. (2001). The limits of a technical concept of a good marriage: Exploring the role of virtue in communication skills. Journal of Marital and Family Therapy, 27(2), 327-340.

Gomide, P. I. C. (2003). Estilos parentais e comportamento anti-social. Em A. Del Prette \& Z. Del Prette (Orgs.), Habilidades sociais, desenvolvimento e aprendizagem: Questões conceituais, avaliação e intervenção (pp. 21-60). Campinas, SP: Alínea.

Guilhardi, H. J., \& Oliveira, W. (2001). Linha de base múltipla: Possibilidades e limites deste modelo de controle de variáveis em situação clínica. Em R. A. Banaco (Org.), Sobre comportamento e cognição: Vol. 1. Aspectos teóricos, metodológicos e de formação em análise do comportamento e terapia cognitivista (pp. 348-384). Santo André, SP: Esetec.

Hunziker, M. H. L. (1982). Considerações metodológicas sobre o estudo da incontrolabilidade. Psicologia, 8, 61-77. 
Hunziker, M. H. L. (1993). Desamparo aprendido: Um modelo animal de depressão? Psicologia: Teoria e Pesquisa, 9, 487-498.

Kohlenberg, R. J., \& Tsai, M. (2001). Psicoterapia analítico funcional: Criando relações terapêuticas e curativas (R. R. Kerbauy, Trad.). Santo André, SP: Esetec. (Trabalho original publicado em 1991)

Leite, S. M. C. S. (2000). Ciúme e inveja: A visão comportamental. Em R. C. Wielenska (Org.), Sobre comportamento e cognição: Vol. 6. Questionando e ampliando a teoria e as intervenções clínicas e em outros contextos (pp. 7477). Santo André, SP: Esetec.

Mead, E. D. (2002). Marital distress, co-occurring depression and marital therapy: A review. Journal of Marital and Family Therapy, 28(3), 299-314.

Morgan, P. (1994). Double income, no kids: The case for the family wage. Em C. Quest (Org.), Liberating women from modern feminism. Londres, Inglaterra: IEA Health.

Osis, M. J. D., Hardy, E., Faúndes, A., Alves, G., \& Balarezo, G. (1994). Opinião das mulheres sobre as circunstâncias em que os hospitais deveriam fazer abortos. Caderno de Saúde Pública, 10(3), 320-330.

Otero, V. R. L., \& Guerrelhas, F. (2003). Saber falar e saber ouvir: A comunicação entre casais. Em F. C. Conte \& M. Z. S. Brandão (Orgs.), Falo ou não falo? (pp. 71-84). Arapongas, PR: Mecenas.

Palácios, M., \& Rego, S. (2006). Bullying: Mais uma epidemia invisível? Revista Brasileira de Educação Médica, 30(1), 3-5.

Penn, M. J. (2008). Microtendências. Rio de Janeiro, RJ: BestSeller.

Pinheiro, M. I. S., Haase, V. G., Del Prette, A., Amarante, C. L. D., \& Del Prette, Z. A. P. (2006). Treinamento de habilidades sociais educativas para pais de crianças com problemas de comportamento. Psicologia: Reflexão e Crítica, 19(3), 407-414.

Regra, J. A. G. (2000). A agressividade infantil. Em E. F. M. Silvares (Org.), Estudos de caso em psicologia clínica comportamental infantil (pp. 79136). Campinas, SP: Papirus.
Reichenheim, M. E., Hasselmann, M. H., \& Moraes, C. L. (1999). Consequências da violência familiar na saúde da criança e do adolescente: Contribuições para a elaboração de propostas de ação. Ciências \& Saúde Coletiva, 4(1), 109-121.

Rios, M. G., \& Gomes, I. C. (2009). Casamento contemporâneo: Revisão de literatura acerca da opção por não ter filhos. Estudos de Psicologia (Campinas), 26(2), 215-225.

Rodrigues Jr., O. M. (2000). Objetos do desejo das variações sexuais, perversões e desvios. São Paulo, SP: Iglu.

Rodrigues Jr., O. M. (2001). O processo terapêutico em sexologia. Em O. M. Rodrigues Jr. (Org.), Aprimorando a saúde sexual (pp. 85-96). São Paulo, SP: Summus.

Rodrigues, M. M. L., \& Hoga, L. A. K. (2005). Homens e abortamento espontâneo: Narrativas das experiências compartilhadas. Revista da Escola de Enfermagem da USP, 39(3), 258-267.

Rosseto, P. P., Rodrigues Jr., O. M., Zeglio, C., \& Catão, E. C. (2006). Vaginismo - relação entre princípios religiosos e a resolução da queixa. Terapia Sexual, 9, 61-74.

Schestatsky, S., \& Fleck, M. (1999). Psicoterapia das depressões. Revista Brasileira de Psiquiatria, 21(1), 41-47.

Sidman, M. (2003). Coerção e suas implicações (M. A. P. A. Andery \& T. M. A. P. Sério, Trads.). Campinas, SP: Livro Pleno. (Trabalho original publicado em 1989)

Silva, L. P., \& Vandenberghe, L. M. A. (2009). Comunicação versus resolução de problemas numa sessão única de terapia comportamental de casal. Revista Brasileira de Terapia Comportamental e Cognitiva, 11(1), 43-60.

Skinner, B. F. (2000). Ciência e Comportamento Humano (R. Azzi, Trad.). São Paulo, SP: Martins Fontes. (Trabalho original publicado em 1953) Skinner, B. F. (1995). O lugar do sentimento na análise do comportamento. Em B. F. Skinner (Org.), Questões recentes na análise comportamental (pp. 13-24; A. L. Neri, Trad.). São Paulo, SP: Papirus (Trabalho original publicado em 1989)

Teykal, C. M., \& Rocha-Coutinho, M. L. (2007). O homem atual e a inserção da mulher no mercado de trabalho. Psicologia (PUCRS), 38(3), 262-268. 
Thomaz, C. R. C. (2005). O efeito da submissão a estressores crônicos e moderados. São Paulo, SP: Educ.

Thomaz, C. R. C. (2009). Possíveis relações entre a submissão ao chronic mild stress (CMS) e o desempenho operante. (Tese de Doutorado nãopublicada). Universidade de São Paulo, São Paulo, SP.

Wagner, A., Predebon, J., Mosmann, C., \& Verza, F. (2005). Compartilhar tarefas? Papéis e funções de pai e mãe na família contemporânea. Psicologia: Teoria e Pesquisa, 21(2), 181186.

Williams, L. C. A. (2006). Pesquisa e intervenção de violência intrafamiliar: Contribuições do laboratório de análise e prevenção da violência (LAPREV). Em Z. V. Freire (Org.), Abusos e proteção de crianças e adolescentes. Rio de Janeiro, RJ: CEIIAS/ISPCAN. 